International Journal of Dairy Processing \& Research (IJDPR)

\title{
Challenges About Determining The Amount Of Melamine In Dairy Products
}

Leandro Freire dos Santos ${ }^{1 *}$, Hélio Hiroshi Suguimoto ${ }^{1}$

${ }^{1}$ Graduate Program in Science and Technology of Dairy Products, University of Northern Paraná (UNOPAR), Brazil.

\section{*Corresponding Author:}

Leandro Freire dos Santos,

Graduate Program in Science and Technology of Dairy Products, University of Northern Paraná (UNOPAR), Brazil.

E-mail: leandrofreire@onda.com.br

Recieved: November 24, 2014

Published: December 10, 2014

Citation: Dos Santos LF, Suguimoto HH (2014) Challenges about Determining The Amount Of Melamine In Dairy Products. Int J Dairy Process Res. 1(2e), 1-2.

doi: http://dx.doi.org/10.19070/2379-1578-140002e

Copyright: dos-Santos $\mathbf{L F}^{\circ}$ 2014. This is an open-access article distributed under the terms of the Creative Commons Attribution License, which permits unrestricted use, distribution and reproduction in any medium, provided the original author and source are credited.

Melamine (IUPAC= 2,4,6-triamine-1,3,5-triazine); $\mathrm{C}_{3} \mathrm{H}_{6} \mathrm{~N}_{6} ; \mathrm{pK}=$ $5.1 ; \mathrm{MW}=126.12 \mathrm{~g} / \mathrm{mol}$; Fig 1 ) is a synthetic compound widely used in the manufacture of resins and plastics to increase thermal resistance, as well it is applied in manufacture of flame retardants, fertilizer, coatings, laminates, adhesives, glues and commercial filters [1-3]. For the first time in 2008, the world was "appalled" by the news that Chinese babies have developed kidney stones caused by consumption of adulterated milk powder. The report of Food Safety Standards Authority of Chine shows that the samples of milk powder contained Melamine [4-5]. Certainly, trace amounts of melamine can be found in foods due to migration from packing walls [6]. However, due to the high nitrogen content (ca. $66 \% \mathrm{w} / \mathrm{w})$ and low cost, melamine has been becoming a common adulterant of dairy products whose aim is to increase the apparent protein content $[1,2]$. Moreover, this adulteration is not easily identified in routine analysis because the non-protein nitrogen cannot be assayed by usual procedures for protein determination, such as Kjeldahl and Dumas [3]. Thus, new methodolo- gies have been developed considering the increasing occurrence of melamine in milk products.

Among these methodologies, high performance liquid chromatography (HPLC), gas chromatography with mass spectroscopy (GC-MS), tandem mass spectrometry (LC-MS), capillary electrophoresis (CE) have shown good accuracy and high sensitivity. However, these methods can also require complicated and timeconsuming procedures, expensive and bulky equipments, high volume of solvent, as well as skilled operators is needed to interpret the results as mass spectral data [8]. On the other hand, some alternative methods have been reported to simplify and accelerate the detection of melamine, such as fluorescence, colorimetric and enzyme linked immunosorbent assay (ELISA). Generally, fluorescence and colorimetric suffer from low selectivity and although ELISA cost relatively low, it was lack of accuracy because of the reaction time of substrate/enzyme [9]. Therefore, studies which focusing on biochemical analysis platforms can offer new insights to reach high sensitive and rapid detection of melamine in milk products.

Biochemical analysis platforms are instruments for bio-analytical measurement. It can offer rapid, inexpensive and automated biochemical analysis platforms. Moreover, it can integrate multiple recognition mechanisms. Guo et al. (2014) interestingly assessed a high sensitive and rapid method for quantifying melamine in milk products by planar waveguide fluorescence immunosensor (PWFI) [1] (Fig. 2) . The system could quantify melamine in a short test time (within $20 \mathrm{~min}$ ) with high recoveries (more than 100 assay cycles). In addition, the authors have concluded that cross-reactivity against some compounds structurally similar to melamine is little.

In conclusion, biochemical analysis platforms are expected to have wide potential applications for onsite and rapid detection of various contaminants in food safety.

Figure 1. Chemical structure of melamine [7]

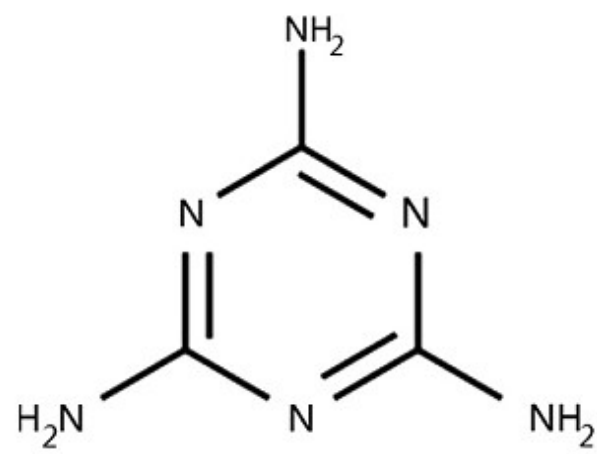


Figure 2. Schematic set-up of PWFI, including sensor, optics, embedded computer and flow delivery system: (a) principle scheme of PWFI and (b) PWFI platform [1].

(a)

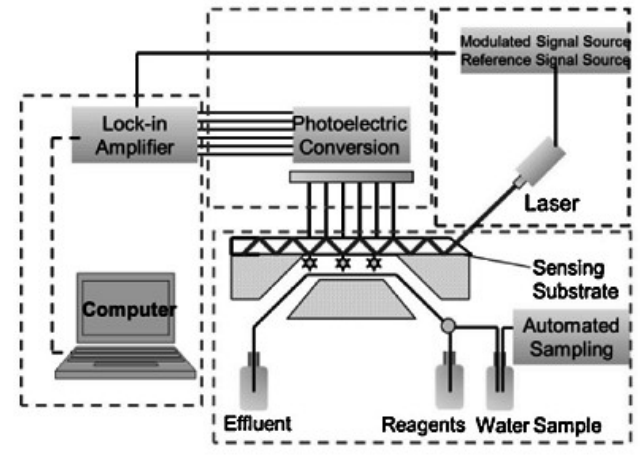

(b)

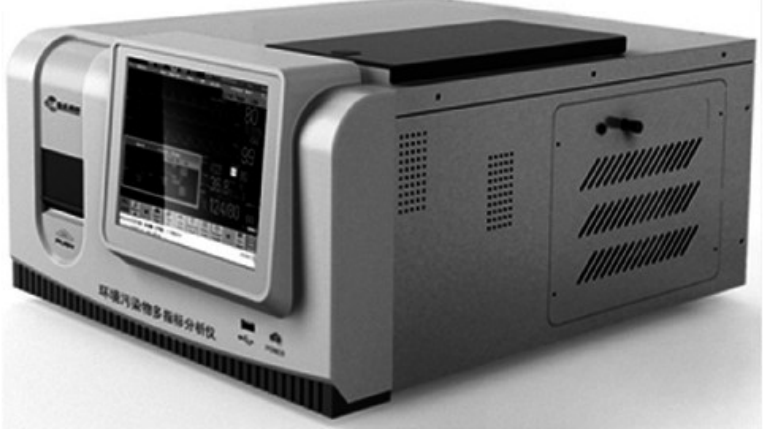

\section{References}

[1]. H. Guo, X. Zhou, Y. Zhang, B. Song, L. Liu, J. Zhang, and H. Shi. Highly sensitive and rapid detection of melamine in milk products by planar waveguide fluorescence immunosensor (PWFI). Sensors and Actuators B-Chemical, 194:114-119, 2014.

[2]. C. F. Nascimento, D. L. Rocha, and F. R. P. Rocha. A fast and environmental friendly analytical procedure for determination of melamine in milk exploiting fluorescence quenching. Food Chemistry, 169:314-319, 2015.

[3]. F. Sun, W. Ma, L. Xu, Y. Zhu, L. Liu, C. Peng, L. Wang, H. Kuang, and C. $\mathrm{Xu}$. Analytical methods and recent developments in the detection of melamine. Trends in Analytical Chemistry, 29(11):1239-1249, 2010.

[4]. R. P. Dalal and D. S. Goldfarb. Melamine-related kidney stones and renal toxicity. Nature Reviews Nephrology, 7:267-274, 2011.

[5]. H. Sun, L. Wang, L. Ai, S. Liang, and H. Wu. A sensitive and validated method for determination of melamine residue in liquid milk by reversed phase high-performance liquid chromatography with solid-phase extraction.
Food Control, 21:686-691, 2010.

6]. B. Brauer and S. Schoene. Simultaneous determination of melamine and formaldehyde after migration from food contact materials. Deutsche Lebensmittel Rundschau, 109:595-601, 2013.

[7]. X. Zhou, X. Wang, K. Chen, X. Mao, W. Peng, and Q. Yu. Melamine detection using phase-shift fiber-loop ring-down spectroscopy. Optics Communications, 333:105-108, 2014.

[8]. P. A. Smith, T. A. Kluchinsky, P. B. Savage, R. P. Erickson, A. P. Lee, K. Williams, M. Stevens, and R. J. Thomas. Traditional sampling with laboratory analysis and solid phase microextraction sampling with field gas chromatography/mass spectrometry by military industrial hygienists. Aihaj, 63:284-292, 2002.

[9]. X. Li, J. Li, H. Kuang, L. Feng, S. Yi, X. Xia, H. Huang, Y. Chen, C. Tang, and Y. Zeng. An ultrasensitive method for the determination of melamine using cadmium telluride quantum dots as fluorescence probes. Analytica Chimica Acta, 802:82-88, 2013. 